\title{
Two new pentanorlanostane metabolites from a soil fungus Curvularia borreriae strain HS-FG-237
}

\author{
Chang-Yan Xue ${ }^{1}$, Jian-Song $\mathrm{Li}^{1}$, Huan $\mathrm{Qi}^{2}$, Feng-Yuan $\mathrm{Xi}^{2}$, Wen-Sheng Xiang ${ }^{1}$, Ji-Dong Wang ${ }^{2}$ and \\ Xiang-Jing Wang ${ }^{1}$
}

The Journal of Antibiotics (2013) 66, 735-737; doi:10.1038/ja.2013.85; published online 28 August 2013

Keywords: Curvalaria borreriae; curvalarols A and B; cytotoxic activity; pentanorlanostane metabolites

Fungi are ubiquitous microorganisms in the soil inhabitants and have been considered as a promising research area for secondary metabolites in recent years. Indeed, $38 \%$ bioactive compounds that have been isolated from microbes so far are produced by fungi. ${ }^{1}$ As illustrated by a number of important products of the pharmaceutical industry such as penicillins, cephalosporins, mevastatin and lovastatin, ${ }^{2}$ fungi are also an important source of useful secondary metabolites. During the course of study of fungi imperfeci as potential sources of new bioactive secondary metabolites, several new compounds have been obtained., Further investigation of an isolate of Curvularia borreriae strain HS-FG-237 collected from samples of loess taken from vegetable plots in Xiangtan of Hunan Province, China, led to the isolation of two new pentanorlanostane metabolites (1-2, Figures 1 and 2), named as curvalarols A (1) and B (2). Here, the report deals with the details of the isolation, structure elucidation and the cytotoxicity of the two new compounds.

The soil fungus C. borreriae strain HS-FG-237 was isolated from samples of loess taken from vegetable plots collected from Xiangtan of Hunan Province, China. It was provided and identified as C. borreriae by the professor Tianyu Zhang at the Shandong Agricultural University, China. The strain HS-FG-237 has been deposited in the Pharmaceutical Research Culture Collection, Zhejiang Hisun Group Co., Ltd, with accession No.: HS-FG-237.

The working strain was grown and preserved on Potato Dextrose Agar (PDA) slant and incubated under static conditions at $24^{\circ} \mathrm{C}$ for 6-7 days. The stock culture was transferred into 1-liter Erlenmeyer flasks containing $250 \mathrm{ml}$ of the seed medium consisting of potato starch (Huling, Huzhou Zhanwang Parmaceutical Co., Ltd, Zhejiang, China) 3\%, glucose (Sinopharm Chemical Reagent Co., Ltd, Shanghai, China) 4\%, peptone (Sincere, Shanghai Sincere Biotech Co. Ltd, Shanghai, China) $0.4 \%, \quad \mathrm{MgSO}_{4} \cdot 7 \mathrm{H}_{2} \mathrm{O}$ (Sinopharm Chemical Reagent Co., Ltd) $0.1 \%, \mathrm{KH}_{2} \mathrm{PO}_{4}$ (Sinopharm Chemical Reagent
Co., Ltd) $0.2 \%$ (natural $\mathrm{pH}$ ) and incubated at $24^{\circ} \mathrm{C}$ for $48 \mathrm{~h}$, shaken at 250 r.p.m. Then, 1 liter of the culture was transferred into a 50-liter fermentor (containing 30-liter fermentation broth), which was composed of peptone $0.5 \%$, potato starch $0.5 \%$, yeast extract (Oxoid Ltd, Basingstoke, Hampshire, UK) $0.2 \%, \mathrm{NaCl}$ (Sinopharm Chemical Reagent Co., Ltd) $0.4 \%, \mathrm{KH}_{2} \mathrm{PO}_{4} 0.1 \%, \mathrm{MgSO}_{4} \cdot 7 \mathrm{H}_{2} \mathrm{O} 0.05 \%, \mathrm{CaCO}_{3}$ (Sinopharm Chemical Reagent Co., Ltd) $0.2 \%$ (pH 6.2-6.4). The fermentation was carried out at $24{ }^{\circ} \mathrm{C}$ for 7 days stirred at 100 r.p.m. with an aeration rate of 900 liters of air per hour.

The mycelial cake and supernatant were separated from the fermentation broth (30 liters) by centrifuge. The resulting cake was extracted with $\mathrm{MeOH}$ (4 liters) and the supernatant was subjected to a Diaion HP-20 resin column and eluted with 95\% EtOH (7 liters). The mixture of $\mathrm{MeOH}$ soluble and $\mathrm{EtOH}$ eluents was evaporated under reduced pressure to obtain a crude extract $(21.4 \mathrm{~g})$ at $50{ }^{\circ} \mathrm{C}$. The crude extract was subjected to a silica gel (Qingdao Haiyang Chemical Group, Qingdao, Shandong, China; 100-200 mesh) column eluted with $\mathrm{CHCl}_{3}-\mathrm{MeOH}$ mixture (100:0-50:50, v/v) to give five fractions (Fr.1 to Fr.5) based on the TLC (HSGF 254, $200 \times 100$, Yantai Chemical Industry Institute, Shandong, China) profiles under UV or by heating after spraying with sulfuric acid-ethanol, 5:95 (v/v). The Fr.2 was chromatographed on a silica gel column and eluted with a stepwise gradient of $\mathrm{CHCl}_{3}-\mathrm{MeOH}$ (99:1, 97:3, 95:5, 93:7, 90:10, $\mathrm{v} / \mathrm{v}$ ) successively to yield two subfractions (Fr.2-1 to Fr.2-2) based on the TLC profiles. The Fr.2-2 was subjected to a Sephadex LH-20 gel column (GE Healthcare, Glies, UK) eluted with EtOH and detected by TLC to give one fraction (Fr.2-2-1). After concentration, the evaporated Fr.2-2-1 was dissolved with $\mathrm{MeOH}$ and a white undissolved substance was presented in Fr.2-2-1. So, the Fr.2-2-1 was filtered to afford a white precipitate and methanol-soluble fraction. The white precipitate dissolved in $\mathrm{CHCl}_{3} / \mathrm{MeOH}(1: 1, \mathrm{v} / \mathrm{v})$ was further purified by semi-preparative HPLC (Agilent 1100, Zorbax

\footnotetext{
${ }^{1}$ Life Science and Biotechnology Research Center, School of Life Science, Northeast Agricultural University, Harbin, China and ${ }^{2}$ Department of New Drug Screening, Zhejiang Hisun Pharmaceutical Co., Ltd, Taizhou, China

Correspondence: Dr J-D Wang, Department of New Drug Screening, Zhejiang Hisun Pharmaceutical Co., Ltd., Taizhou 318000, China.

E-mail: jdwang@hisunpharm.com

or Professor X-J Wang, School of Life Science, Northeast Agricultural University, No. 59, Mucai Street, Xiangfang District, Harbin 150030 , China.

E-mail: wangneau@163.com
}

Received 29 April 2013; revised 11 July 2013; accepted 26 July 2013; published online 28 August 2013 
SB-C18, $5 \mu \mathrm{m}, 250 \times 9.4 \mathrm{~mm}$ i.d.; $1.5 \mathrm{ml} \mathrm{min}^{-1}$; $220 \mathrm{~nm}$; Agilent, Palo Alto, CA, USA) eluting with $\mathrm{MeOH}-\mathrm{H}_{2} \mathrm{O}$ (85:15, v/v) to obtain compound $1\left(t_{R} 20.2 \mathrm{~min}, 8.5 \mathrm{mg}\right)$. The methanol-soluble fraction was subsequently isolated by semi-preparative HPLC using $\mathrm{MeOH}-$ $\mathrm{H}_{2} \mathrm{O}(93: 7, \mathrm{v} / \mathrm{v})$ to obtain compound $2\left(\mathrm{t}_{\mathrm{R}} 14.5 \mathrm{~min}, 7.0 \mathrm{mg}\right)$. The ESIMS and HRESIMS spectra were taken on a Q-TOF Micro LC-MSMS mass spectrometer (Milford, MA, USA). ${ }^{1} \mathrm{H}$ and ${ }^{13} \mathrm{C}$ NMR spectra were measured with a Bruker DRX-400 $\left(400 \mathrm{MHz}\right.$ for ${ }^{1} \mathrm{H}$ and $100 \mathrm{MHz}$ for ${ }^{13} \mathrm{C}$ ) spectrometer (Rheinstetten, Germany).

Compound 1, a white amorphous powder with m.p. $194-195^{\circ} \mathrm{C}$ and $[\alpha]_{D}^{25} 43^{\circ}$ (c 0.05, EtOH), had a molecular formula of $\mathrm{C}_{26} \mathrm{H}_{42} \mathrm{O}_{4}$ as deduced from the HRESIMS $\left(\mathrm{m} / z\right.$ 441.2962 $[\mathrm{M}+\mathrm{Na}]^{+}$, calcd 441.2975 for $\left.\left[\mathrm{C}_{26} \mathrm{H}_{42} \mathrm{NaO}_{4}\right]^{+}\right)$. The UV spectrum of 1 showed absorption maxima at $209 \mathrm{~nm}(\log \varepsilon 3.58)$. The IR spectrum showed absorption bands due to the hydroxyl group $\left(3380 \mathrm{~cm}^{-1}\right)$ and carbonyl group $\left(1719 \mathrm{~cm}^{-1}\right)$. The ${ }^{1} \mathrm{H}$ NMR $\left(400 \mathrm{MHz}, \mathrm{CDCl}_{3}\right)$ spectrum of 1 indicated five singlet methyl group $(\delta 0.67$ (s), 0.81 $(\mathrm{s}), 0.92(\mathrm{~s}), 0.99(\mathrm{~s})$, and $1.00(\mathrm{~s}))$, an aliphatic doublet methyl $(\delta$ $1.29(\mathrm{~d}, J=7.0 \mathrm{~Hz})$ ), two oxygenated methine protons $(\delta 3.24$ (dd, $J=4.5,11.6 \mathrm{~Hz}), 4.11(\mathrm{t}, J=7.8 \mathrm{~Hz}))$ and a methoxy group $(\delta 3.65$ (s)). Its ${ }^{13} \mathrm{C}$ and DEPT NMR spectra revealed 26 carbon resonances including an ester carbonyl at $\delta 178.2$ (s); two oxygenated methine carbons at $\delta 72.2(\mathrm{~s}), 78.8(\mathrm{~s})$; two $s p^{2}$ quaternary carbons at $\delta 134.1$ (s), $135.5(\mathrm{~s})$; four aliphatic quaternary carbons at $\delta 36.9(\mathrm{~s}), 38.8(\mathrm{~s})$, 48.8 (s) and 52.3 (s); three aliphatic methines at $\delta 41.3$ (d), 48.7 (d) and 50.4 (d); and one methoxy carbon at $\delta 51.2$ (q), in addition to six methyls and seven methylenes. Except the methoxy group, the above ${ }^{1} \mathrm{H}$ and ${ }^{13} \mathrm{C}$ NMR data (Table 1) indicated that 1 should be a tetracyclic pentanortriterpenoid or sesterterpenoid analog. Comparison of the ${ }^{1} \mathrm{H}$ and ${ }^{13} \mathrm{C}$ NMR data of 1 with those of 23,24,25,26,27pentanorlanost-8-ene-3 $\beta, 22$-diol (3), ${ }^{5,6}$ suggested that $\mathbf{1}$ was structurally related to 3 . The differences between 1 and 3 could be explained by the replacement of the hydroxymethyl and C-12 methylene in 3 by a methoxycarbonyl group and an oxymethine, respectively, in 1. This result was further confirmed by the HMBC correlations (Figure 3) from $\delta_{\mathrm{H}} 3.65\left(\mathrm{OCH}_{3}\right)$ and $1.29\left(\mathrm{H}_{3}-21\right)$ to $\delta_{\mathrm{C}} 178.2(\mathrm{C}-22)$ and from $\delta_{\mathrm{H}} 0.67\left(\mathrm{H}_{3}-18\right)$ to $\delta_{\mathrm{C}} 72.2(\mathrm{C}-12)$. As a consequence, the gross structure of 1 was established (Figure 1).

The relative configuration of $\mathbf{1}$ was assigned by analogy with $\mathbf{3}$ and the NOESY correlation (Figure 3) between $\mathrm{H}-3$ and $\mathrm{H}-5, \mathrm{H}_{3}-28$, between $\mathrm{H}_{3}-30$ and $\mathrm{H}-17, \mathrm{H}-12$, and between $\mathrm{H}_{3}-18$ and $\mathrm{H}-20$.

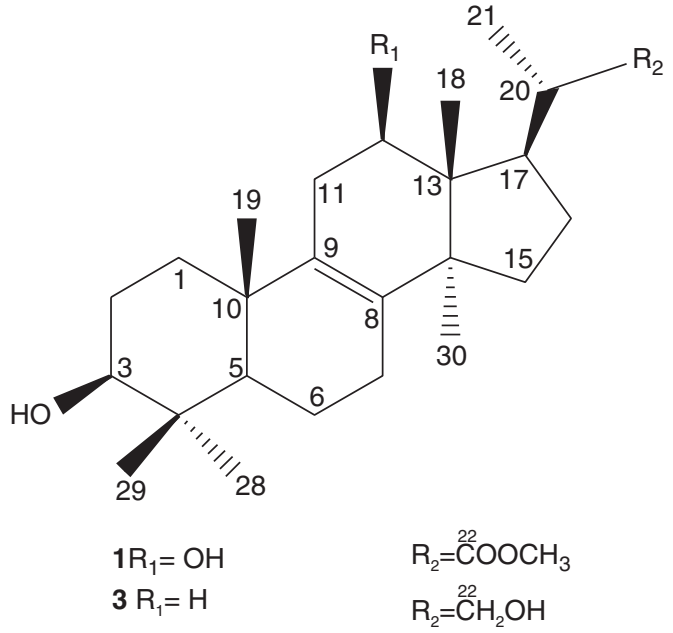

Figure 1 The structures of compounds 1 and 3 .
Compound 2 was obtained as colorless oil with $[\alpha]_{\mathrm{D}}^{25} 21^{\circ}(c 0.08$, EtOH). Its molecular formula was established to be $\mathrm{C}_{25} \mathrm{H}_{38} \mathrm{O}_{2}$ by the HRESIMS data $\left(m / z 371.2950[\mathrm{M}+\mathrm{H}]^{+}\right.$, calcd 371.2945). The UV spectrum of 2 showed absorption maxima at $226 \mathrm{~nm}(\log \varepsilon 3.63), 215 \mathrm{~nm}(\log \varepsilon 3.62)$. The ${ }^{1} \mathrm{H}$ NMR spectrum of 2 display five singlet methyl group at $\delta 0.76$ (s), $0.89(\mathrm{~s}), 1.08(\mathrm{~s}), 1.16(\mathrm{~s})$ and $1.23(\mathrm{~s})$, a $s p^{3}$ doublet methyl at

Table $1{ }^{1} \mathrm{H}$ and ${ }^{13} \mathrm{C}$ NMR data for compounds 1 and 2 (in $\mathrm{CDCl}_{3}$ )

\begin{tabular}{|c|c|c|c|c|}
\hline \multirow[b]{2}{*}{ Position } & \multicolumn{2}{|c|}{$\delta_{H}(J$ in $H z)$} & \multicolumn{2}{|c|}{$\delta_{C}$} \\
\hline & 1 & 2 & 1 & 2 \\
\hline \multirow[t]{2}{*}{1} & $1.24(\mathrm{~m})$ & $7.26(d, 10.4)$ & $35.7(t)$ & $156.5(d)$ \\
\hline & $1.72(\mathrm{~m})$ & & & \\
\hline \multirow[t]{2}{*}{2} & $1.60(\mathrm{~m})$ & $5.90(d, 10.4)$ & $27.8(\mathrm{t})$ & $126.0(d)$ \\
\hline & $1.68(\mathrm{~m})$ & & & \\
\hline 3 & $3.24(\mathrm{dd}, 4.5,11.6)$ & & $78.8(\mathrm{~s})$ & $205.0(\mathrm{~s})$ \\
\hline 4 & & & $38.8(\mathrm{~s})$ & $44.3(\mathrm{~s})$ \\
\hline 5 & $1.02(\mathrm{dd}, 2.1,12.9)$ & $1.91(\mathrm{~m})$ & $50.4(d)$ & $47.6(d)$ \\
\hline \multirow[t]{2}{*}{6} & $1.49(\mathrm{~m})$ & $1.75(\mathrm{~m})$ & $18.1(\mathrm{t})$ & $18.3(t)$ \\
\hline & $1.68(\mathrm{~m})$ & & & \\
\hline 7 & $2.02(\mathrm{~m})$ & $2.18(\mathrm{~m})$ & $26.1(\mathrm{t})$ & $25.5(t)$ \\
\hline 8 & & & $134.1(\mathrm{~s})$ & $136.4(\mathrm{~s})$ \\
\hline 9 & & & $135.5(\mathrm{~s})$ & $131.0(\mathrm{~s})$ \\
\hline 10 & & & $36.9(\mathrm{~s})$ & 40.3 (s) \\
\hline \multirow[t]{2}{*}{11} & $2.58(\mathrm{~m})$ & $2.24(\mathrm{~m})$ & $33.9(t)$ & $22.4(t)$ \\
\hline & $1.72(\mathrm{~m})$ & & & \\
\hline 12 & $4.11(t, 7.8)$ & $1.81(\mathrm{~m})$ & $72.2(\mathrm{~s})$ & $30.7(t)$ \\
\hline 13 & & & $48.8(\mathrm{~s})$ & $44.7(\mathrm{~s})$ \\
\hline 14 & & & $52.3(\mathrm{~s})$ & $49.6(s)$ \\
\hline \multirow[t]{2}{*}{15} & $1.20(\mathrm{~m})$ & $1.26(\mathrm{~m})$ & $31.0(t)$ & $30.8(t)$ \\
\hline & $1.68(\mathrm{~m})$ & $1.67(\mathrm{~m})$ & & \\
\hline \multirow[t]{2}{*}{16} & $1.68(\mathrm{~m})$ & $1.42(\mathrm{~m})$ & $25.4(t)$ & $27.6(t)$ \\
\hline & $1.90(\mathrm{~m})$ & $1.94(\mathrm{~m})$ & & \\
\hline 17 & $2.15(\mathrm{~m})$ & $1.61(\mathrm{~m})$ & 48.7 (d) & $46.8(d)$ \\
\hline 18 & $0.67(\mathrm{~s})$ & $0.76(\mathrm{~s})$ & $9.4(q)$ & $16.0(q)$ \\
\hline 19 & 0.99 (s) & $1.24(\mathrm{~s})$ & $19.1(q)$ & $23.1(q)$ \\
\hline 20 & $2.70(\mathrm{~m})$ & $1.59(\mathrm{~m})$ & $41.3(d)$ & $39.4(d)$ \\
\hline 21 & $1.29(\mathrm{~d}, 7.0)$ & $1.05(\mathrm{~d}, 6.2)$ & $18.8(q)$ & $16.8(q)$ \\
\hline \multirow[t]{2}{*}{22} & & $3.36(\mathrm{dd}, 6.0,10.7)$ & $178.2(\mathrm{~s})$ & $68.1(t)$ \\
\hline & & $3.65(\mathrm{dd}, 2.6,10.7)$ & & \\
\hline 28 & $0.81(\mathrm{~s})$ & $1.16(\mathrm{~s})$ & $15.4(q)$ & $26.2(q)$ \\
\hline 29 & $1.00(\mathrm{~s})$ & $1.08(\mathrm{~s})$ & $28.0(q)$ & $21.4(q)$ \\
\hline 30 & $0.92(\mathrm{~s})$ & $0.89(\mathrm{~s})$ & $24.1(q)$ & $23.9(q)$ \\
\hline $\mathrm{OCH}_{3}$ & 3.65 (s) & & $51.2(q)$ & \\
\hline
\end{tabular}

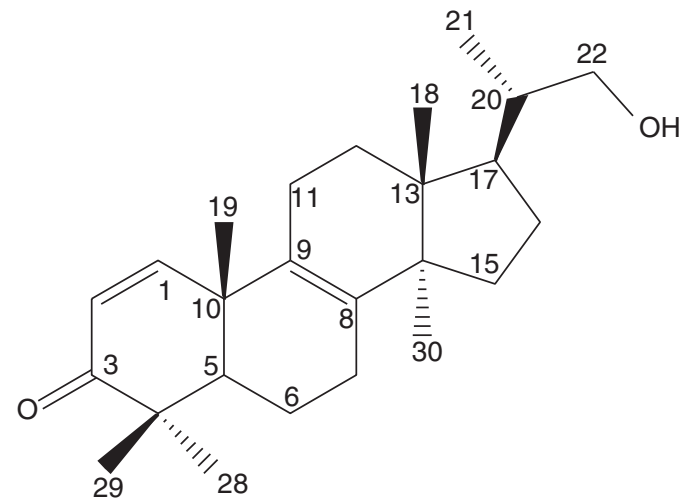

Figure 2 The structure of compound 2 . 


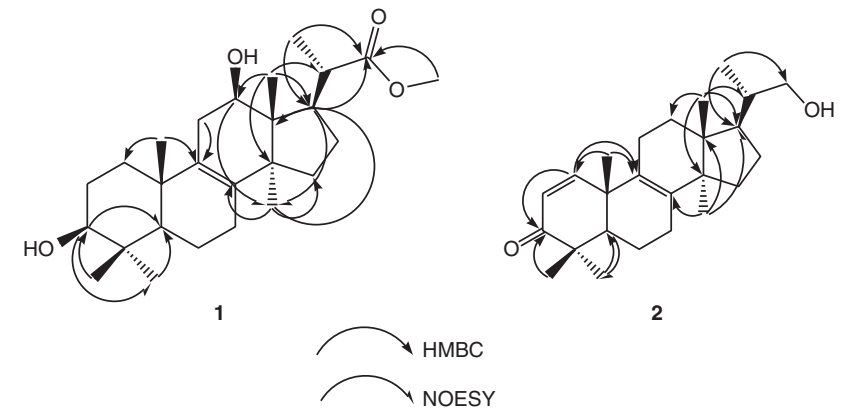

Figure 3 The key HMBC and NOESY correlations of $\mathbf{1}$ and $\mathbf{2}$.

$\delta 1.05$ (d) and two olefinic protons at $\delta 5.90(1 \mathrm{H}, \mathrm{d}, J=10.4 \mathrm{~Hz})$ and $7.26(1 \mathrm{H}, \mathrm{d}, J=10.4 \mathrm{~Hz})$. Its ${ }^{13} \mathrm{C} \mathrm{NMR}$ spectra showed 25 carbon signals composing six methyl carbons, seven aliphatic methylene carbons, one of which was bearing an oxygen function $(\delta 68.1)$, three aliphatic methine carbons, four $s p^{3}$ quaternary carbons, two $s p^{2}$ methines, two $s p^{2}$ quaternary carbons and a conjugated carbonyl $(\delta$ 205.0). An $\alpha, \beta$-unsaturated ketone was present by analysis of the HMBC correlations (Figure 3) from $\delta_{\mathrm{H}} 7.26(\mathrm{H}-1)$ to $\delta_{\mathrm{C}} 205.0(\mathrm{C}-3)$ and the NMR data. Except the $\alpha, \beta$-unsaturated ketone moiety, the ${ }^{1} \mathrm{H}$ and ${ }^{13} \mathrm{C}$ NMR data (Table 1) of 2 was similar to those of $\mathbf{3}$ and suggested that 2 was also a derivative of 3 . By detailed analysis of the NMR data of $\mathbf{2}$ and 3, it was revealed that the secondary alcohol and two methylenes in 3 were substituted by the $\alpha, \beta$-unsaturated ketone. The HMBC correlations from $\mathrm{H}_{3}-19$ to $\delta_{\mathrm{C}} 156.5$ (C-1) and from $\mathrm{H}_{3}-28$ and $\mathrm{H}_{3}-29$ to $\delta_{\mathrm{C}} 205.0$ (C-3) indicated the placement of the $\alpha, \beta$ unsaturated ketone in $\mathbf{2}$. Thus, the planar structure of $\mathbf{2}$ was established as shown in Figure 2.
The relative stereochemistry of $\mathbf{2}$ was assigned as those of $\mathbf{1}$ and $\mathbf{3}$ by analysis of the NMR data and the NOESY correlations (Figure 3) from $\mathrm{H}_{28}$ to $\mathrm{H}-5$, from $\mathrm{H}_{3}-30$ to $\mathrm{H}-17$ and from $\mathrm{H}-18$ to $\mathrm{H}-20$.

The cytotoxicities of compounds $\mathbf{1}$ and $\mathbf{2}$ were assayed in vitro against the A549, K562 and MDA-MB-231 cell lines by the CCK8 colorimetric method as described in our previous papers. ${ }^{7,8}$ Compound 1 exhibited cytotoxic activity with $\mathrm{IC}_{50}$ values of 21.9, 23.5 and $17.7 \mu \mathrm{g} \mathrm{ml}^{-1}$, respectively. The values of compound 2 were $15.3,11.1$ and $13.3 \mu \mathrm{g} \mathrm{ml}^{-1}$.

\section{ACKNOWLEDGEMENTS}

This research work was financially supported by the Special Program for the Science and Technology Plan of Zhejiang Province of China, under Grant no. 2012C03006-2, the National Key Project for Basic Research (2010CB126102) and the National Natural Science Foundation of China (30771427 and 31000884).

1 Demain, A. L. \& Sanchez, S. Microbial drug discovery: 80 years of progress. J. Antibiot. 62, 5-16 (2009).

2 Keller, N. P., Turner, G. \& Bennett, J. W. Fungal secondary metabolism-from biochemistry to genomics. Nat. Rev. Microbiol. 12, 937-994 (2005).

3 Zhang, $\mathrm{H}$. et al. Two new metabolites from a soil fungus Curvularia affinis strain HS-FG196. J. Asian Nat. Prod. Res. 14, 1078-1083 (2012).

4 Pang, Y. W. et al. Two new antitumor constituents from a soil fungus Curvularia inaequalis (strain HS-FG-257). J. Antibiot. 66, 287-289 (2013).

5 Hosoe, T. et al. A new pentanorlanostane derivative, cladosporide A, as a characteristic antifungal agent against Aspergillus fumigatus, isolated from Cladosporium sp. Chem. Pharm. Bull. 48, 1422-1426 (2000).

6 Grove, J. F. 23,24,25,26,27-Pentanorlanost-8-en-3 $\beta, 22$-diol from Verticillium lecanii. Phytochemistry. 23, 1721-1723 (1984).

7 Wang, J. D. et al. HSO71, a new furan-type cytotoxic metabolite from Streptomyces sp. HS-HY-071. J. Antibiot. 61, 623-626 (2008).

8 Wang, J. D. et al. Five new epothilone metabolites from Sorangium cellulosum strain So0157-2. J. Antibiot. 62, 483-487 (2009). 